Radiologe 2014 · 54:922

DOI 10.1007/s00117-014-2744-1

Online publiziert: 17. September 2014

c) Springer-Verlag Berlin Heidelberg 2014

\author{
U. Müller ${ }^{1}$ S. Ulmer ${ }^{2} \cdot$ R. Schlaeger ${ }^{3,4} \cdot$ F. Ahlhelm ${ }^{1}$ \\ ${ }^{1}$ Institut für Radiologie, Kantonsspital Baden AG, Baden \\ ${ }_{2}^{2}$ Medizinisch-Radiologisches Institut, Zürich \\ ${ }^{3}$ Neurologische Klinik und Poliklinik, Universitätsspital Basel, Basel \\ ${ }^{4}$ Department of Neurology, UCSF, San Francisco
}

\title{
Erratum zu: Pädiatrische intraspinale Neoplasien
}

In der HTML-Version dieses Beitrags ist die Teilabbildung $4 a$ leider entfallen, dafür wurde die Teilabbildung $4 b$ doppelt abgebildet. In der gedruckten Version des Beitrags sowie im Online-PDF ist die Abbildung korrekt, wie hier angegeben (- Abb. 1), dargestellt.

Wir bitten den Fehler zu entschuldigen.

Die Redaktion

\section{Korrespondenzadresse}

\section{PD Dr. F. Ahlhelm}

Institut für Radiologie,

Kantonsspital Baden AG,

5404 Baden, Schweiz

frank.ahlhelm@gmail.com
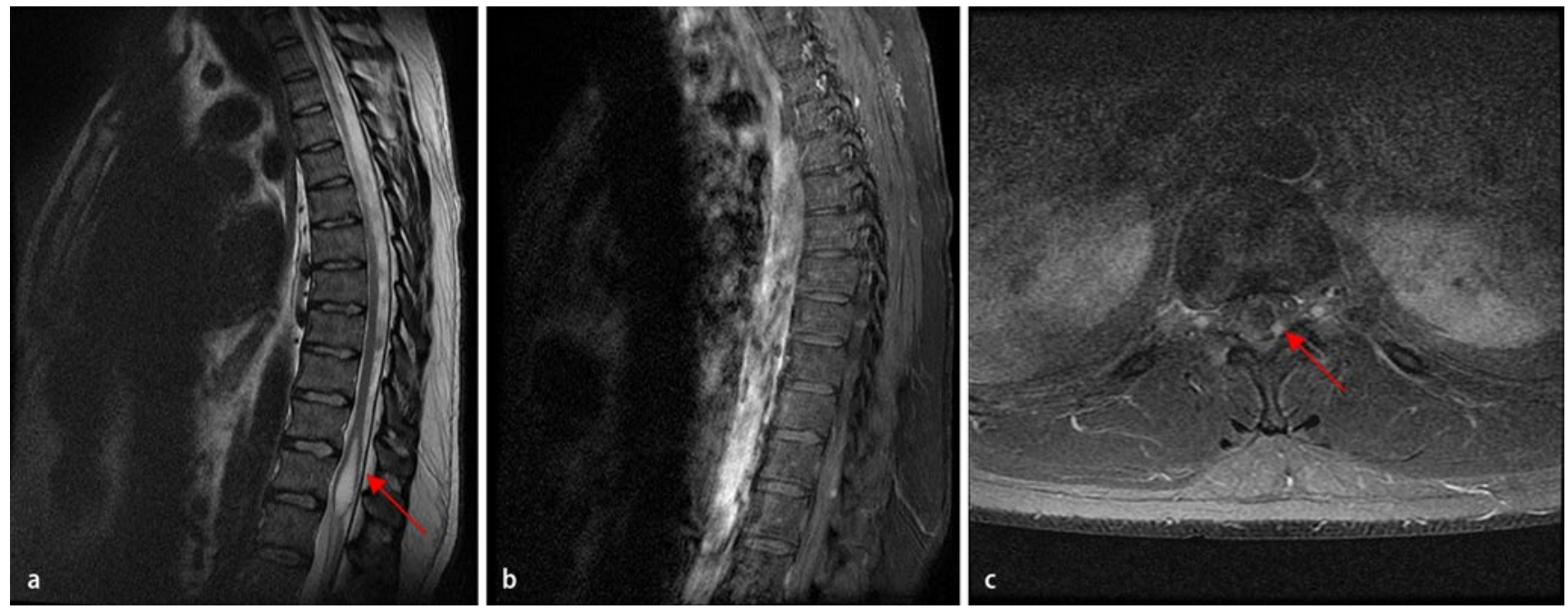

Abb. 1 \ Hämangioblastom. In der sagittaler T2w-Sequenz (a) Nachweis einer zystischen Formation im Konusbereich. Nach Kontrastmittel(KM)-Gabe in sagittaler (b) und axialer (c) T1-gewichteter fettsupprimierter Untersuchungstechnik Nachweis einer nodulär KM-affinen Tumorformation perimedullär dorsolateral links (Pfeile). Die meisten Hämangioblastome sind jedoch v. a. zervikal zu erwarten. Sie können jedoch auch thorakal und im Konusbereich auftreten, wie dieses Beispiel zeigt 